\title{
EXPRESSION OF CD10 AS A PROGNOSTIC AND PREDICTIVE FACTOR IN UROTHELIAL CARCINOMAS
}

\author{
H. Popov*, P. Ghenev \\ Department of General and Clinical Pathology, Forensic Sience and Deontology, Medical University, \\ Varna, Bulgaria
}

\begin{abstract}
Purpose: The aim of the study is to compare the expression of CD10 in invasive and non-invasive urothelial carcinomas.

Methods: Primary sites of 40 cases of urothelial carcinomas were studied on H\&E stained sections from the original biopsy paraffin block, out of them, 20 - with and another 20 - without smooth muscle invasion. For CD 10 expression routine immunohistochemical procedure was applied, using DAKO FLEX monoclonal mouse antihuman clon 56C6.

Results: Two groups - invasive and non-invasive urothelial cancers were compared in regard to CD10 expression. The results definitely reveal that most of the cells in all invasive cancers express CD10, while in non-invasive cancers CD10 expresion was absent.

Conclusion: The results provide convinsing evidense for CD10 role in urothelial cancer invasiveness in underlying smooth muscle.
\end{abstract}

Key words: CD10, urothelial carcinoma, invasive

\section{INTRODUCTION}

CD10 is a cell membrane metalloprotein which participates in the postsecretory processing of neuropeptides, inactivating inflammatory and vasoactive peptides. Thus, it plays a role in the regulation of cell growth, differentiation, adhesion, invasion, and angiogenesis via enzymatic hydrolysis of various peptide hormones $(1,2,3)$. CD10 is expressed in normal and neoplastic tissues $(3,4)$; in neoplastic processes, CD10 is expressed at different stages in the course of the disease. Studies conducted on human tumors reveal that CD10 activity exerts different influences on different tumor types (5-9). Loss of CD10 expression in prostate $(10,11)$, lung (12), and endometrial tumors (13) accelerates tumor development and progression. And in these tumors, CD10 is thought to function as a tumor suppressor. In melanomas (14), breast cancers (15), and colon tumors (16), CD10 expression is associated with progression and metastasis. Few studies have investigated CD10 activity in urinary bladder tissues, and their results are substantially different. Particularly, urothelial

\footnotetext{
*Correspondence to: Popov H., Department of General and Clinical Pathology, Forensic Sience and Deontology, Medical University - Varna, Bulgaria, phone: 052/978 273, e-mail: popov12@abv.bg
}

carcinoma shows statistically significant difference in the staining intensity (0-3+) between dysplasia, low and high grade cancers. Urothelial carcinomas reveal CD10 expression (focal in low grade and diffuse in high grade), unlike cases with urothelial dysplasia in which CD10 expression is negative (17). Furthermore, CD10 expression significantly correlates with certain parameters in urothelial carcinomas, such as advanced stage, tumor size, and shorter survival (18-20). In addition, CD10 expressing cells are supposed to have increased potential for invasion and metastases. In this regard, literary data are incomplete and even contradictory. The aim of the study is to compare the expression of CD10 in invasive and non-invasive urothelial carcinomas.

\section{MATERIALS AND METHODS}

Primary sites of 40 cases of urothelial carcinoma were studied on H\&E stained sections from the original biopsy paraffin block, out of them, 20 - with and another 20 without smooth muscle invasion. For CD10 expression routine immunohistochemical procedure was applied, using DAKO FLEX monoclonal mouse antihuman clon 56C6.

\section{RESULTS}

We compared the expression of CD10 in two groups of invasive and non-invasive urothelial 
cancers. The results definitely reveal that most of the cells in all invasive cancers express CD10 (findings illustrated in Figure 1a) and all non-invasive cancers are composed of predominantly CD10 negative cells (Figure 1b). The normal covering epithelium (best visible in Figure 1b) is also intensively

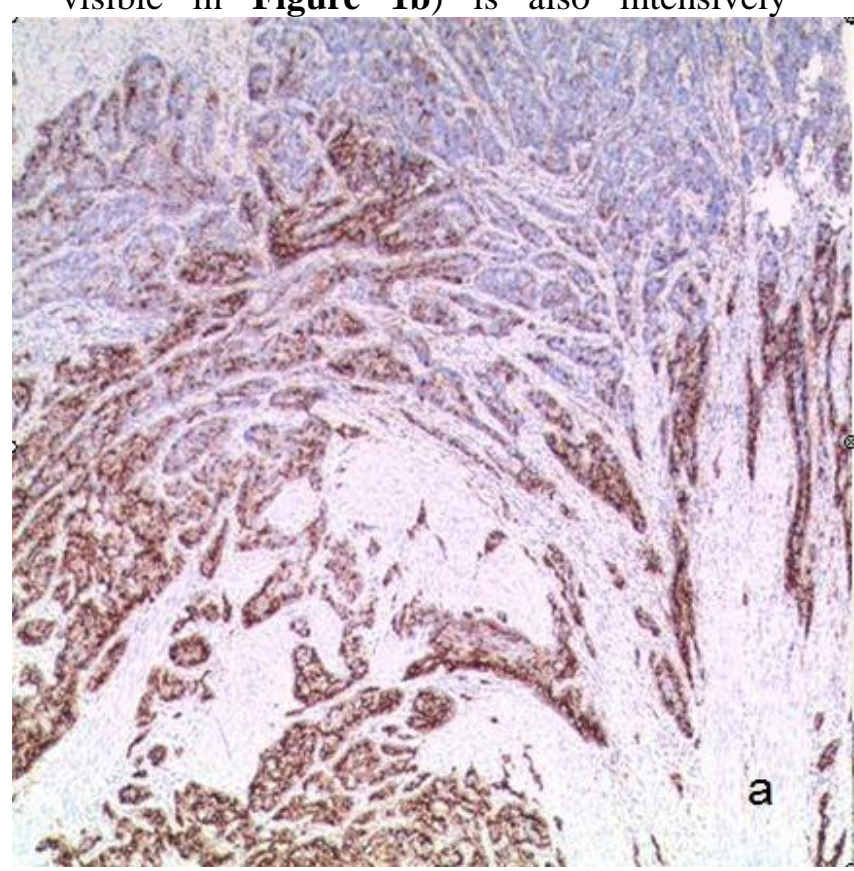

Figure 1. Invasive urothelial cancer, intensive positive CD10 expression, especially in the regions of deep invasion, original madnification $\mathrm{x} 40$, (a); non-nvasive urothelial cancer, negative CD10 expression in the cancer cells and positive reaction in the adjacent normal covering epithelium and occasional stromal cells, original madnification $\mathrm{x} 40,(\mathbf{b})$.

\section{DISCUSSION}

Our results demonstrate an evident link between CD10 expression and higher stage of the tumor in contrast with other reports that CD10 expresion is found to be related to the histologic grade only (21). In addition, our findings show a correlation between the invasive properties of the tumor and CD10 expression.

On the other hand, it is suggested that CD10 is widely expressed in noninvasive urothelial carcinoma (4), while Bircan et al. obtained results similar to ours and reported an inverse correlation. Also, Iwaya et al. wrote about some possible $\mathrm{CD} 10$ role in urothelial tumorogenesis. In particular, these authors suggest that CD10 is capable to enhance cancer cells invasion and metastasis. A number of other studies also discuss CD10 regulating biological activities of peptide substanses by reducing the concentration for receptor binding and signal transduction $(18,19,23)$. Furthermore, Cutrona et al. and Sumitoto et al. anounce a possible association between CD10 expression and apoptosis.

Having in mind these contradictory data, we believe that our results provide convinsing evidense at least for CD10 role in urothelial positive compared to the adjacent entirely negative cancer. In addition, some single, or grouped $\mathrm{CD}$ positive cells scattered in the stroma or arranged perivascularly were also present. Their eventual significance remains to be further elucidated.

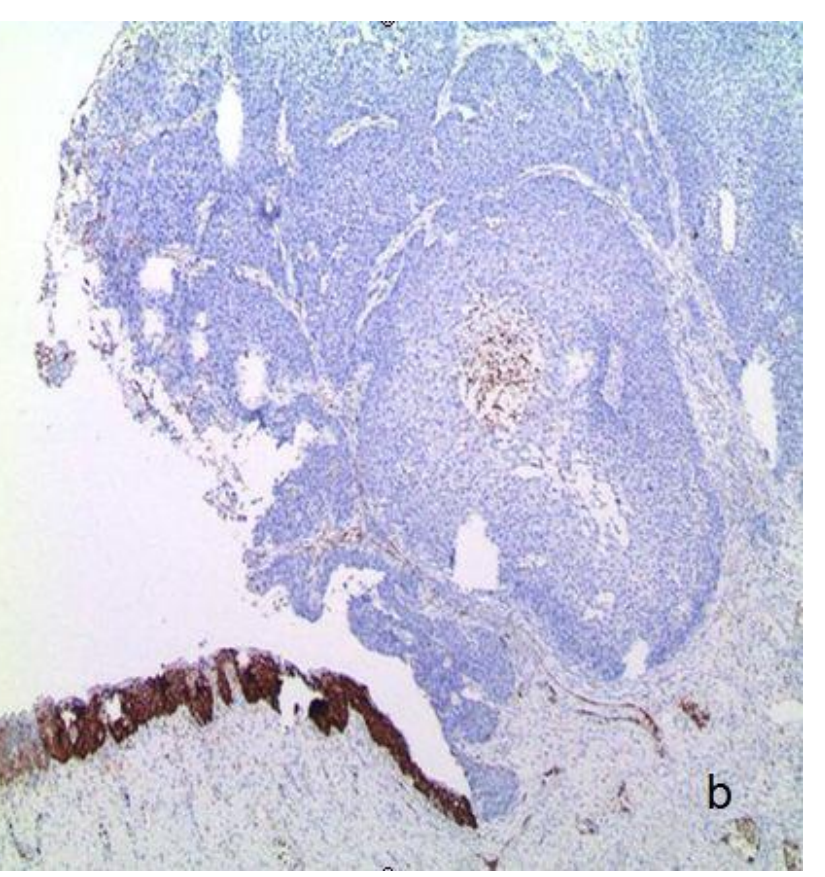


6. Dogan, A., Bagdi, E., Munson, P., Isaacson, P. CD10 and bcl-6 expression in paraffin sections of normal lymphoid tissue and Bcell lymphomas. Am J Surg Pathol, 24:846-852, 2000.

7. Metzgar, R., Borowitz, M., Jones, N., Dowell, B. Distribution of common acute lymphoblastic leukemia antigen in nonhematopoietic tissues. $J$ Exp Med, 154:1249-1254, 1981.

8. Kaufmann, O., Flath, B., Spдth-Schwalbe, E., Possinger, K., Dietel, M. Immunohistochemical detection of CD10 with monoclonal antibody 56C6 on paraffin sections. Am J Clin Pathol, 111:117-122, 1999.

9. Mc Intosh, G., Lodge, A., Watson, P., Hall, A., Wood, K., Anderson, J., Angus, B., Horne, C., Milton, I. NCL-CD10-270: a new monoclonal antibody recognizing CD10 in paraffin-embedded tissue. Am $J$ Pathol, 154:77-82, 1999.

10.Sumitomo, M., Shen, R., Walburg, M., Dai, J., Geng, Y., Navarro, D., Dai, J., Asano, T., Hayakawa, M., Nanus, D. Neutral endopeptidase inhibits prostate cancer cell migration by blocking focal adhesion kinase signaling. J Clin Invest, 106:13991407, 2000.

11.Dai, J., Shen, R., Sumitomo, M., Goldberg, J., Geng, Y., Navarro, Xu, D., Koutcher, J., Garzotto, M., Powell, C., Nanus, D. Tumor suppressive effects of neutral endopeptidase in androgen-independent prostate cancer. Clin Cancer Res, 7:1370-1377, 2001.

12.Ganju, R., Sunday, M., Tsarwhas, D., Card, A., Shipp, M. CD10/ NEP in non-small cell lung carcinomas: relationship to cellular proliferation. J Clin Invest, 94(5):17841791, 1994.

13.Chu, P., Arber, D., Weiss, L., Chang, K. Utility of CD10 in distinguishing between endometrial stromal sarcoma and uterine smooth muscle tumors: an immunohistochemical comparison of 34 cases. Mod Pathol, 14(5):465-71, 2001.

14.Kanitakis, J., Narvaez, D., Claudy, A.
Differential expression of the CD10 antigen (neutral endopeptidase) in primary versus metastatic malignant melanomas of the skin. Melanoma Res, 12:241-244, 2002.

15.Iwaya, K., Ogawa, H., Izumi, M., Kuroda, M., Serizawa, H., Koyanagi, Y., Mukai, K. Stromal expression of CD10 in invasive breast carcinoma: a new predictor of clinical outcome. Virchows Arch, 440:589593, 2002.

16.Ogawa, H., Iwaya, K., Izumi, M., Kroda, M., Serizawa, H., Koyanagi, Y., Mukai, K. Expression of CD10 by stromal cells during colorectal tumor development. Hum Pathol, 33:806-811, 2002 .

17.Bircan, S., Candir, O., Kapucuoglu, N., Serel, T., Ciris, M., Karahan, N. CD10 expression in urothelial bladder carcinomas: A pilot study. Urol IntI, 77:107-113, 2006.

18.Cheng, L., Neumann, R., Nehra, A., Spotts, B., Weaver, A., Bostwick, D. Cancer heterogeneity and its biologic implications in the grading of urothelial carcinoma. Cancer, 88:1663-1670, 2000.

19.Lee, R., Droller, M. The natural history of bladder cancer: implications for therapy. Urol Clin N Am, 27:1-13, 2000.

20.Cheng, L., Cheville, J., Neumann, R., Bostwick, D. Natural history of urothelial dysplasia of the bladder. Am J Surg Pathol, 23:443-447, 1999.

21.Murali, R., Delprado, W. CD10 immunohistochemical staining in urothelial neoplasms. Am J Clin Pathol, 124:371-9, 2005.

22.Kim, M., Kim, S. Immunhistochemical profile of common epithelial neoplasms arising in the kidney. Appl Immunohistochem Mol Morphol, 154: 7782, 2002.

23.Cutrona, G., Leanza, N., Ulivi, M., Melioli, G., Burgio, V., Mazzarello, G., Gabutti, G., Roncella, S., Ferrarini, M. Expression of CD10 by human $\mathrm{T}$ cells that undergo apoptosis both in vitro and in vivo. Blood, 94:3067-3076, 1999. 